\title{
PHYSIOLOGICAL CHARACTERISTICS OF DIFFERENT CULTIVARS OF APRICOT
}

\section{Titova Nina}

Institute of Genetics, Physiology and Plant Protection of the Academy of Sciences of Moldova, Chisinau,

Republic of Moldova

\section{ФИЗИОЛОГИЧЕСКИЕ ОСОБЕННОСТИ РАЗНЫХ СОРТОВ АБРИКОСА}

\section{Титова Нина}

Received 25.6. 2017

Revised 28. 6. 2017

Published 30. 11. 2017

For the Republic of Moldova is particularly important selection of apricot cultivars with high adaptability to varying local conditions. Comprehensive experimental studies are needed to evaluate promising cultivars introduced from the international assortment. This report presents the results of studying during 2015-2016 the features of growth and photosynthetic ability of perspective for Moldova apricot cultivars: the four-year-old fruiting apricot plants late Sirena cultivar, two-year-old plants of the Salah cultivar with early-middle ripening period and Vasile Cochu early cultivar were studied. Plants were grown in the IGPP ASM lyzimeters. The dynamics of growth processes (specific leaf mass, leaf area), the rate of photosynthesis and transpiration using LCl device, net photosynthetic productivity, pigment fund by spectrophotometric method were studied. The obtained data show the strategy of the deployment of the leaf surface in the test cultivars: the fruiting plants of the Sirena cultivar were distinguished by the enhanced accumulation of the biomass of the leaves during the periods after flowering, growth and especially ripening of the fruit. The weight of such leaves exceeds the average values for young plants of Salah and Vasile Cochu cultivars by 17.65 and $22.10 \%$, respectively. This corresponds to the same differences between cultivars in the specific mass leaves. The net productivity of photosynthesis, which characterizes the potential productivity of the studied cultivars, constitutes on average for unfruitful plants of Salah and Vasile Cochu cultivars respectively 59 and $51 \%$ of the values of the Sirena cultivar fruiting. The carried out researches have revealed features of growth processes, intensity of photosynthesis, transpiration and net productivity of photosynthesis different perspective cultivars of apricot. This testifies to the existence of a number of closely interconnected processes that serve as a mechanism for realizing the action of the genetic plan for the manifestation of different maturation periods for fruits and plant productivity.

Keywords: apricot; cultivars; growth; photosynthesis; transpiration

\section{Введение}

Усиленному поиску новых сортов плодовых культур, в том числе и абрикоса, уделяется в Молдове значительное внимание (Babuc, 2012). Для Республики Молдова особенно важен подбор сортов абрикоса с высокой адаптируемостью к переменным местным условиям, генетической устойчивостью к морозу и высоким физиологическим потенциалом

\footnotetext{
*Corresponding author: Nina Titova, Institute of Genetics, Physiology and Plant Protection of the Academy of Sciences of Moldova, Chisinau, Republic of Moldova, $\triangle$ nvtmd@mail.ru
} 
уравновешивания роста и плодоношения. Необходимы всесторонние экспериментальные исследования для оценки перспективных сортов, введенных из международного ассортимента (Babuc, 2012; Păntea, 2016).

В течение ряда лет в лаборатории фотосинтеза Института генетики, физиологии и защиты растений АН Молдовы совместно с отделом питомниководства НПО Кодру нами изучались физиолого-биохимические особенности ряда сортов абрикоса, произрастающих в промышленном питомнике, саду, и в условиях вегетационного опыта в лизиметрах (Şişсаnu et. al., 2008; Титова и Шишкану, 2016). Особое внимание при этом уделялось формированию и функционированию фотосинтетического аппарата растений разного возраста и с разными сроками созревания плодов, характеризующих физиологическое состояние и продуктивность растений (Титова и др., 2013; Титова, 2015).

Цель работы - изучение особенностей формирования и функционирования фотосинтетического потенциала растений абрикоса, определяющих продуктивность новых перспективных сортов.

\section{Материалы и методы}

В течение 2015 - 2016 г.г. в лизиметрах вегетационного комплекса Института генетики, физиологии и защиты растений АНМ изучали 4 - 5 летние плодоносящие растения абрикоса позднеспелого сорта Сирена, двухлетние растения сортов Шалах с ранне - средним сроком созревания плодов и раннего сорта Василе Кочу. Определяли сезонную динамику важнейших параметров фотосинтетической продуктивности: формирование и развитие листовой поверхности (площадь, удельная поверхностная плотность листьев), чистую продуктивность фотосинтеза растений абрикоса (Ничипорович и др., 1961). Газометрическое определение интенсивности фотосинтеза и транспирации листьев абрикоса проводили с помощью прибора $\mathrm{LCl}$ (Англия), содержание хлорофиллов а и 6 и каротиноилов определяли в ацетоновой вытяжке спектрофотометрически. Достоверность различий между вариантами оценивали с использованием критерия Стьюдента при 0,05 \% уровне значимости.

\section{Результаты и их обсуждение}

Полученные данные показывают стратегию развертывания листовой поверхности у изучаемых сортов: плодоносящие растения сорта Сирена отличаются усиленным накоплением биомассы листьев в периоды после цветения, роста и особенно созревания плодов (табл. 1). Масса листьев у них превышает в среднем величины у молодых растений сортов Шалах и Василе Кочу соответственно на 17,65 и 22.10 \%. Такое преимущество сорта Сирена по массе листьев позволяет более высокое накопление ассимилятов направить на рост и урожай.

Таблица 1 Накопление биомассы листьев разных сортов абрикоса, мг сухой массы/дм² Table 1 Biomass accumulation of leaves of different cultivars of apricot, $\mathrm{mg}$ dry weight $/ \mathrm{dm}^{2}$

\begin{tabular}{|c|c|c|c|c|}
\hline Сорт / Дата & 6 - 25 мая & 31 мая - 7 июня & 7 - 16 июня & 16 - 30 июня \\
\hline Сирена & $238 \pm 11,5$ & $149 \pm 7,4$ & $168 \pm 8,4$ & $271 \pm 13,0$ \\
\hline Шалах & $213 \pm 10,5$ & $129 \pm 6,2$ & $103 \pm 5,2$ & $159 \pm 7,9$ \\
\hline Василе Кочу & $186 \pm 9,3$ & $130 \pm 6,3$ & $126 \pm 6,1$ & $122 \pm 6,0$ \\
\hline
\end{tabular}

Это соответствует таким же различиям между сортами в удельной поверхностной плотности листьев (табл. 2). 
Таблица 2 Динамика удельной поверхностной плотности листьев абрикоса в течение вегетации, мг сухой массы/см²

Table 2 Dynamics of a specific mass of apricot leaves during the growing season, $\mathrm{mg}$ dry weight $/ \mathrm{cm}^{2}$

\begin{tabular}{|l|c|c|c|c|c|c|}
\hline Сорт / Дата & $\mathbf{6}$ мая & $\mathbf{2 5}$ мая & $\mathbf{7}$ июня & $\mathbf{1 6}$ июня & $\mathbf{3 0}$ июня & $\mathbf{7}$ июля \\
\hline Сирена & 8,2 & 9,57 & 9,4 & 10,04 & 11,74 & 11,22 \\
\hline Шалах & 6,63 & 8,45 & 8,36 & 8,44 & 10,22 & 10,09 \\
\hline Василе Кочу & 5,97 & 7,77 & 7,77 & 8,46 & 9,68 & 10,76 \\
\hline
\end{tabular}

Сезонная динамика хлорофиллов и каротиноидов у исследуемых растений однотипна, что подтверждает наличие единого типа стратегии накопления пигментов у разных сортов абрикоса. Пигментный фонд сильнорослого сорта Шалах, как правило, превосходит другие сорта. Однако в июне во время созревания плодов у плодоносящих растений сорта Сирена сумма хлорофиллов и особенно соотношение хлорофиллов а и б было самым высоким (Титова и др., 2017).

В то же время интенсивность фотосинтеза и транспирации у разных сортов находится на близком уровне, отличаясь только в июле при созревании плодов у с. Сирена и закладке почек у с. Василе Кочу.

Для плодоносящих растений сорта Сирена и молодых растений сорта Василе Кочу в середине июля характерно повышение соотношения фотосинтеза и транспирации, что свидетельствует о повышении накопления сухого вещества на единицу поглощенной воды (табл. 3). Это создает дополнительный резерв мощности в случае запроса на ассимиляты.

Таблица 3 Отношение интенсиности фотосинтеза к интенсивности транспирации в листьях абрикоса

Table 3 Ratio of photosynthesis intensity to the transpiration intensity in the apricot leaves

\begin{tabular}{|l|c|c|c|c|}
\hline Сорт / Дата & $\mathbf{1 2}$ мая & $\mathbf{2 4}$ мая & $\mathbf{2 3}$ июня & $\mathbf{1 9}$ июля \\
\hline Сирена & 2,41 & 2,12 & 2,28 & 2,9 \\
\hline Шалах & 1,31 & 2,13 & 1,22 & 5,4 \\
\hline Василе Кочу & 2,66 & 2,04 & 1,05 & 5,21 \\
\hline
\end{tabular}

Как и по накоплению биомассы и удельной поверхностной плотности листьев, чистая продуктивность фотосинтеза листьев абрикоса с. Сирена превосходит её у сортов Шалах и Василе Кочу во время роста и созревания плодов (табл. 4).

Таблица 4 Чистая продуктивность фотосинтеза листьев разных сортов абрикоса (мг/дм²/час)

Table 4 Net productivity of photosynthesis of apricot different cultivars leaves $\left(\mathrm{mg} / \mathrm{dm}^{2} / \mathrm{h}\right)$

\begin{tabular}{|l|c|c|c|c|}
\hline Сорт / Дата & $\mathbf{6 - 2 5}$ мая & $\mathbf{3 1}$ мая - 7 июня & $\mathbf{7 - 1 6}$ июня & $\mathbf{1 6 - 3 0 ~ и ю н я ~}$ \\
\hline Сирена & $\mathbf{0 , 5 5}$ & 0,89 & 0,62 & 0,81 \\
\hline Шалах & 0,49 & 0,23 & 0,37 & 0,47 \\
\hline Василе Кочу & 0,43 & 0,77 & 0,32 & 0,36 \\
\hline
\end{tabular}

Чистая продуктивность фотосинтеза, характеризующая потенциальную продуктивность исследуемых сортов, составляла, к примеру, за период 7 - 16 июня у неплодоносящих 
растений сортов Шалах и Василе Кочу соответственно 59 и 51 \% от значений у плодоносящего сорта Сирена. Во время созревания урожая (16 - 30 июня) нетто-фотосинтез у сорта Сирена увеличился с 0,62 до 0,81 мг/дм²/час и превышал величины чистой продуктивности фотосинтеза у сортов Шалах и Василе Кочу соответственно в 1,72 и 2,25 раза. Урожайность плодоносящих 5-летних растений абрикоса сорта Сирена в лизиметрах составляла в среднем 4675 г плодов с одного растения.

\section{Выводы}

Таким образом, выявлены особенности формирования и функционирования фотосинтетического аппарата, содержания пигментов в листьях, интенсивности фотосинтеза, транспирации и чистой продуктивности фотосинтеза, характеризующие перспективные сорта абрикоса. Это свидетельствует о наличии ряда тесно взаимосвязанных процессов, служащих механизмом в реализации генетического плана разного срока созревания плодов и продуктивности растений абрикоса.

\section{Литература}

Babuc, V. 2012. Pomicultura. Chishinau:Tipografia Centrală, 663 p. ISBN 978-9975-53-067-5.

Pintea, M. 2016. Manifestation of apricot self-compatibility and self-(in) compatibility in the conditions of the Republic of Moldova. J.Botany, vol. 8, no.1 (12), p. 17-20.

Şişcanu, Gh. et. al. 2008. Estimarea fiziologo-biochimică şi bioenergetică a acţiunii bioregulatorilor naturali din clasa glicozidelor steroidice asupra plantelor de cais. Diminuarea impactului factorilor redicţionării extremale asupra plantelor de cultură. Chişinău, p. 138-145.

Ничипорович, А.А. и др. 1961. Фотосинтетическая деятельность растений в посевах. М. АН СССР, $134 \mathrm{c}$.

Титова, Н.В., Шишкану, Г.В. 2016. Взаимосвязь процессов роста и фотосинтеза в растениях абрикоса. Mediul ambiant, no. 1, p. 9-12. ISBN 1810-9551.

Титова, Н.В. 2015. Характеристика пигментного фонда листьев разных сортов абрикоса. Матер. конфер. «Фундаментальные и прикладные проблемы современной экспериментальной биологии растений». ИФР РАН, М. с. 658-662.

Титова, Н.В., Пынтя, М., Шишкану, Г.В. 2017. Изучение пигментного фонда и фотосинтетической активности листьев разных сортов абрикоса. Матер. VI Межд. н. конфер. «Селекційно-генетична наука і освіта». Умань, с. 250-253.

Титова, Н.В., Шишкану, Г.В., Малина, Р.Б., Мащенко, Н.Е. 2013. Действие натурального препарата линарозид на фотосинтез и пигменты плодоносящих растений абрикоса. Mатер. Всерос. н. конфер.«Факторы устойчивости растений в экстремальных природных условиях и техногеннной среде». Иркутск, с. 257-259. ISBN 978-5-918344-512-4. 